\title{
Long non-coding RNA SNHG20 promotes colorectal cancer cell proliferation, migration and invasion via miR-495/STAT3 axis
}

\author{
YU WANG $^{1}$, JIANYING FU ${ }^{1}$, LILI YANG $^{1}$ and ZHI LIANG ${ }^{2}$ \\ ${ }^{1}$ Department of Gastroenterology Endoscopy, Linyi Central Hospital, Linyi, Shandong 276400; ${ }^{2}$ Department of Anorectal \\ Surgery, The First Affiliated Hospital of University of South China, Hengyang, Hunan 421001, P.R. China
}

Received December 31, 2019; Accepted October 2, 2020

DOI: $10.3892 / \mathrm{mmr} .2020 .11669$

\begin{abstract}
Colorectal cancer (CRC) is one of the primary causes of cancer-associated mortality worldwide. However, the potential molecular mechanism of CRC progression remains unknown. Long non-coding RNA small nucleolar RNA host gene 20 (SNHG20) has been demonstrated to be involved in the development and progression of a variety of tumors, including CRC. However, the involvement of SNHG20 in CRC progression remains unclear. The aim of the present study was to investigate the functional role and molecular mechanism of SNHG20 in CRC progression. In the present study, SNHG20 expression was found to be significantly upregulated in CRC tissues and cell lines. Association analysis indicated that high SNHG20 expression was significantly association with greater tumor size $(\mathrm{P}=0.014)$, tumor invasion depth $(\mathrm{P}=0.019)$, positive lymph node status $(\mathrm{P}=0.022)$, distant metastasis $(\mathrm{P}=0.017)$ and advanced tumor node metastasis stage $(\mathrm{P}=0.038)$. Loss-of-function experiments indicated that SNHG20 knockdown could significantly suppress proliferation, migration and invasion in vitro. Notably, SNHG20 knockdown significantly inhibited tumor growth and lung metastasis in vivo. Bioinformatics analysis and luciferase reporter assays confirmed that microRNA (miR)-495 was a direct target of SNHG20. Rescue assays indicated that miR-495 inhibitor reversed the suppressive effects of SNHG20 knockdown on CRC progression. Moreover, STAT3 was identified as a downstream target of miR-495 in CRC. STAT3 overexpression partially rescued the inhibitory effects of SNHG20 knockdown on CRC progression. Taken together, the results revealed that SNHG20 facilitated CRC progression by regulating STAT3 expression and by sponging miR-495.
\end{abstract}

Correspondence to: Dr Zhi Liang, Department of Anorectal Surgery, The First Affiliated Hospital of University of South China, 69 Chuan Shan Road, Hengyang, Hunan 421001, P.R. China E-mail: liang1420178784@163.com

Key words: colorectal cancer, small nucleolar RNA host gene 20, microRNA-495, STAT3, progression

\section{Introduction}

Colorectal cancer (CRC) is one of the most common digestive carcinomas. According to the statistics, there were $>1.8$ million new colorectal cancer cases and 881,000 deaths occurred in 2018 worldwide (1). Although therapeutic strategies have been considerably improved, the 5-year survival rate of patients with CRC with distant metastasis was estimated to be $11.7 \%$ due to the unclear molecular mechanisms underlying tumor metastasis and progression are unclear $(2,3)$. Therefore, further investigation of the underlying molecular mechanisms associated with the progression of CRC is required for improving disease prognosis.

Long non-coding RNAs (lncRNAs) are a type of non-coding RNA with an approximate length of $>200$ nucleotides (4). Previously, it was confirmed that lncRNAs are dysregulated in various human cancers, suggesting that they may participate in several biological processes in cancers, including cancer progression (5). For instance, Hua et al (6) demonstrated that overexpression of NNT-AS1 could enhance cell proliferation and invasion via the Wnt/b-catenin signaling pathway. Ge et al (7) revealed that CAR10 expression is increased in lung adenocarcinoma and that it is correlated with the proliferation, migration and invasiveness of lung adenocarcinoma cells. Small nucleolar RNA host gene 20 (SNHG20), located on chromosome 17q25.2, was initially identified as an oncogenic gene involved in hepatocellular carcinoma (8). Subsequent studies demonstrated that SNHG20 is associated with the progression of various types of cancers. For example, SNHG20 expression is significantly upregulated in non-small cell lung cancer (NSCLC), suggesting that it acts as an oncogene (9). SNHG20 promotes oral squamous cell carcinoma cell proliferation and tumor growth by competitively sponging microRNA (miR/miRNA)-197 (10). Wu et al (11) demonstrated that SNHG20 upregulation contributes to the growth and metastasis of prostate cancer cells via the miR-6516-5p/SCGB2A1 pathway. In addition, a previous study indicated that SNHG20 expression is notably upregulated in colorectal cancer. Elevated levels of SNHG20 are correlated with advanced tumor node metastasis (TNM) stage and poor survival (12). However, the pivotal roles and potential molecular mechanisms of SNHG20 regulation in CRC have not been fully elucidated. Therefore, the present 
study aimed to investigate the underlying molecular mechanisms of SNHG20 in CRC progression.

In the present study, the data revealed that the expression levels of SNHG20 were significantly elevated in CRC tissues and cell lines. In addition, functional experiments indicated that SNHG20 knockdown inhibited CRC cell proliferation, migration and invasion. It is important to note that silencing of SNHG20 expression significantly inhibited tumor growth and metastasis in vivo. Knockdown of SNHG20 expression suppressed CRC progression. This was achieved by suppressing STAT3 expression via sponging miR-495.

\section{Materials and methods}

Tissue samples and cell culture. A total of 68 matched CRC tissues and corresponding normal tissues were collected at The First Affiliated Hospital of the University of South China (Hengyang, China). Signed informed consent had been provided by all patients. None of the patients received chemotherapy or radiotherapy prior to surgical resection. The present study was approved by the Medical Ethics Committee of The First Affiliated Hospital of University of South China (approval no. LL20181102013).

Normal colorectal epithelial cells (FHC) and human CRC cells (HCT116, SW480, SW620, HT-29) were provided by The Cell Bank of Type Culture Collection of the Chinese Academy of Sciences. The cell lines were authenticated by STR profiling. The cells were grown in RPMI-1640 medium (Gibco; Thermo Fisher Scientific, Inc.) supplemented with 10\% fetal bovine serum (Invitrogen; Thermo Fisher Scientific, Inc.) and $1 \%$ penicillin/streptomycin antibiotics (Invitrogen; Thermo Fisher Scientific, Inc.) in the presence of $5 \% \mathrm{CO}_{2}$ at $37^{\circ} \mathrm{C}$.

Cell transfection. Lentiviral knockdown vector specifically targeting SNHG20 [small interfering (si) RNA-SNHG20] and negative control (si-NC) were provided by Shanghai GenePharma Co.,Ltd. miR-495 mimics, miR-495 inhibitor and their NCs were purchased from Shanghai GenePharma Co., Ltd. STAT3 overexpression plasmid [pcDNA3.1(+) STAT3] and its NC [pcDNA3.1(+)] were constructed by Shanghai GenePharma Co., Ltd. Before transfection, cells were subcultured in 6-well plates (Corning, Inc.) $\sim 50 \%$ confluence $\left(3 \times 10^{5}\right)$. RNAs (100 nM) or miR-495 mimics (50 nM) or miR-495 inhibitor $(150 \mathrm{nM})$ or plasmids $(1.5 \mu \mathrm{g}$ per well) were transfected into cells. The lentivirus was prepared according to the User Manual of the Lenti-Pac ${ }^{\mathrm{TM}}$ HIV Expression Packaging kit (GeneCopoeia, Inc.). The viral packaging was performed in $293 \mathrm{~T}$ cells after co-transfection of the Lv3-si-SNHG20, or empty lentiviral vector, and Lenti-Pac ${ }^{\mathrm{TM}}$ HIV packaging mix (GeneCopoeia, Inc.) using EndoFectin ${ }^{\mathrm{TM}}$ Lenti transfection reagent (GeneCopoeia, Inc.). The medium containing the retroviral supernatant was harvested $48-72 \mathrm{~h}$ after transfection. The retroviruses were added into HCT116 and SW480 cells for the infection. The cells were selected by culture in the presence of puromycin $(5 \mu \mathrm{g} / \mathrm{ml}$; Invitrogen; Thermo Fisher Scientific, Inc.) for up to 2 weeks. The sequences were as follows: si-SNHG20, 5'-GCCUAGGAUCAUCCAGGUUTT-3'; si-NC, 5'-UUCUCCGAACGUGUCACGUU-3'; miR-495 mimic, 5'-UGUGACGAAACAAACAUGGUGCACU-3'; miR-NC,
5'-CAGUACUUUUGUGUAGUACAA-3'; miR-495 inhibitor, 5'-GCCGAATTCTGGCTGCTATGATCTGAACT-3'; and inhibitor NC, 5'-CAGUACUUUUGUGUAGUACAA-3'. In order to establish the STAT3-overexpression cell model, the full-length cDNAs of human STAT3 were cloned into the pc-DNA3.1 vector. Transfection was performed when the cell density was $50 \%$.All cells transfections were conducted using Lipofectamine ${ }^{\circledR} 2000$ (Invitrogen; Thermo Fisher Scientific, Inc.). Transfection was performed at room temperature for $30 \mathrm{~min}$. After incubation for $48 \mathrm{~h}$, the cells were collected for the subsequent experiments.

Reverse transcription-quantitative PCR (RT-qPCR). Total RNA was isolated from tissue and cells with TRIzol ${ }^{\circledR}$ reagent (Invitrogen; Thermo Fisher Scientific, Inc.). The mRNA expression levels of SNHG20 and STAT3 were detected following RNA extraction and RT-qPCR. Total RNA was reverse transcribed into cDNA using a Reverse Transcription kit (Takara Bio, Inc.). The PCR protocol consisted of cycling at $94^{\circ} \mathrm{C}$ for $3 \mathrm{~min}$, followed by 30 cycles of $94^{\circ} \mathrm{C}$ for $30 \mathrm{sec}, 55^{\circ} \mathrm{C}$ for $30 \mathrm{sec}$ and $72^{\circ} \mathrm{C}$ for $60 \mathrm{sec}$ and a final extension at $72^{\circ} \mathrm{C}$ for 5 min. RT-qPCR was carried out with SYBR Green (Takara Bio, Inc.). The expression levels of miR-495 were measured using the miRNA isolation kit (Guangzhou RiboBio Co., Ltd.). GAPDH and U6 were used as internal controls for RNAs and miRNAs, respectively. The relative expression levels of the genes were determined using the $2^{-\Delta \Delta C q}$ method (13). The primers used are shown in Table I.

Cell viability assays. The cell proliferative rates were assessed by MTS and colony formation assays. The transfected cells were seeded in 96-well plates $\left(2 \times 10^{3}\right.$ cells/well) with five replicate wells. At the time of harvest, $10 \mu 1$ MTS was added to each well. Following incubation for $2 \mathrm{~h}$, the absorbance was read at $490 \mathrm{~nm}$ on a microplate reader (Bio-Rad Laboratories, Inc.). The colony formation assay was performed with transfected cells seeded in 6-well plates (800/well) and incubated for 2 weeks. Subsequently, the cells were fixed with ethanol at room temperature for $10 \mathrm{~min}$ and stained with $0.1 \%$ crystal violet at room temperature for $10 \mathrm{~min}$. when a single colony cell number $>50$ was achieved. Finally, colony counting was performed under an inverted light microscope (magnification, x200; CKX41, Olympus).

Transwell migration and invasion assays. The Transwell assay was carried out to assess the migratory (without Matrigel) and invasive (with Matrigel; BD Biosciences) ability of the cells. The BD Matrigel was placed in a $4^{\circ} \mathrm{C}$ refrigerator for $24 \mathrm{~h}$. It was diluted to 1:9 ratios with RPMI-1640. The upper Transwell chamber was filled with $50 \mu \mathrm{l}$ of the diluent. The Transwell insert was incubated for $3 \mathrm{~h}$ at $37^{\circ} \mathrm{C}$ until the Matrigel clotted. Briefly, the transfected cells $\left(5 \times 10^{4}\right.$ cells/well) were seeded into the upper Transwell chamber with $250 \mu \mathrm{l}$ serum-free RPMI-1640 medium, and the lower chamber was filled with $750 \mu 1$ RPMI-1640 medium supplemented with 10\% FBS. Following incubation for $48 \mathrm{~h}$ at $37^{\circ} \mathrm{C}$, the invaded cells were fixed with ethanol at room temperature for $10 \mathrm{~min}$ and stained with $0.1 \%$ crystal violet at room temperature for $10 \mathrm{~min}$. The stained cells were counted using an inverted light microscope (magnification, x200; CKX41, Olympus Corporation). 
Table I. Primers used for reverse transcription-quantitative PCR analysis.

\begin{tabular}{ll}
\hline Gene & \multicolumn{1}{c}{ Primer sequences $\left(5^{\prime} \rightarrow 3^{\prime}\right)$} \\
\hline SNHG20 & F: ATGGCTATAAATAGATACACG \\
& R: GGTACAAACAGGGAGGGA \\
miR-495 & F: GCGGAAACAAACATGGTGCA \\
U6 & F: CTCGCTTCGGCA GCACA \\
STAT3 & F: CAGCAGCTTGACACACGGTA \\
GAPDH & R: AAACACCAAAGTGGCATGTGA \\
& F: GCGAGATCGCACTCATCATCT \\
& R: TCAGTGGTGGACCTGACC
\end{tabular}

F, forward; R, reverse; SNHG20, small nucleolar RNA host gene 20; miR, microRNA.

Dual-luciferase reporter assay. The StarBase software V2.0 (http://starbase.sysu.edu.cn) was applied to analyze the potential miRNA target of SNHG20. The TargetScan software was performed to predict the potential mRNA target of miR-495. The wild-type (WT) or mutant (MUT) SNHG20 sequences containing the miR-495 binding sites were cloned into the pmir-GLO Dual-luciferase vector (Promega Corporation) and co-transfected with the miR-495 mimics or corresponding control sequences into the cells with Lipofectamine 2000. Following transfection, the cells were incubated for $48 \mathrm{~h}$ and the luciferase activity was measured with the Dual Luciferase Reporter Assay System (Promega Corporation). Similarly, pmirGLO-STAT3-WT or pmirGLO-STAT3-MUT were constructed and co-transfected with miR-495 mimics or the corresponding control into the cells. Following transfection, the cells were incubated for $48 \mathrm{~h}$ and the luciferase activity was measured. The Renilla luciferase was used as an internal control to homogenize the detection of the reporter gene.

Western blot analysis. Total protein from tissues or cells was extracted using pre-cooled RIPA lysis. Protein concentration was evaluated using the BCA protein assay regents (cat. no. 23225, Pierce; Thermo Fisher Scientific, Inc.). Equal amounts (50 $\mu \mathrm{g} / \mathrm{lane})$ of protein aliquots were loaded on to $10 \%$ SDS-PAGE gels, then, proteins transferred onto PVDF membranes. After blocking with 5\% skimmed milk for $2 \mathrm{~h}$ at room temperature, the membranes were then incubated with primary antibodies at $4^{\circ} \mathrm{C}$ overnight. Next, the membranes were incubated with secondary antibody for $1 \mathrm{~h}$ at room temperature. The primary antibodies used in the present study were as follows: STAT3 (1:1,000; cat. no. 9139; Cell Signaling Technology, Inc.) and GAPDH (1:3,000; cat. no. 8245; Abcam). The secondary antibody used was HRP-conjugated goat anti-rabbit $\operatorname{IgG}$ (1:2,000; cat. no. 6728; Abcam). The immunoblots were detected using LI-COR Odyssey ${ }^{\circledR}$ CLX Two-colour infrared laser imaging system (LI-COR Biosciences). ImageJ software V1.8.0 (National Institutes of Health) was implemented to perform densitometric analysis.

RNA immunoprecipitation (RIP) assay. RIP assays were performed using the Magna RIP ${ }^{\mathrm{TM}}$ kit (EMD Millipore).
Briefly, the cells were lysed using complete RIP lysis buffer $\left(4^{\circ} \mathrm{C} ; 1,000 \mathrm{x} \mathrm{g} ; 10 \mathrm{~min}\right)$ and incubated with containing magnetic beads $(2 \mu \mathrm{g})$ conjugated with human anti-Ago2 antibody (Abcam; cat. no. ab186733) or anti-IgG antibody (EMD Millipore; cat. no. MA5-27548) for overnight at $4^{\circ} \mathrm{C}$. Samples were washed with ethanol and sodium acetate and incubated with proteinase $\mathrm{K}$ at $55^{\circ} \mathrm{C}$ for $30 \mathrm{~min}$ to isolate the RNA-protein complexes from beads $\left(4^{\circ} \mathrm{C} ; 1,000 \mathrm{x} \mathrm{g} ; 15 \mathrm{~min}\right)$. Lastly, RT-qPCR assays were performed to determine SNHG20 and miR-495 expression.

Tumor xenograft mouse models. Ten male nude mouse (age, 5-6 weeks; weight, 18-20 g) were housed in an isolated, clean, air-conditioned room at a temperature of $25-26^{\circ} \mathrm{C}$ and a relative humidity of $\sim 50 \%$, light $12 \mathrm{~h} /$ day. The mice were randomly divided into two groups ( $\mathrm{n}=5 /$ group). All rats were given free access to water and food. SW480 cells were stably transfected with si-SNHG20 lentivirus or si-NC $\left(2 \times 10^{6}\right.$ cells/mouse; $n=5$ for each group). A total of $5 \times 10^{6}$ cells suspended in $100 \mu \mathrm{l}$ PBS were subcutaneously inoculated into the right flanks of each nude mouse (the mice were provided by the Experimental Animal Center of the Chinese Academy of Sciences). Tumor size was measured once every 4 days following the appearance of the tumors and calculated using the following formula: $\mathrm{V}\left(\mathrm{mm}^{3}\right)=$ width $^{2}\left(\mathrm{~mm}^{2}\right)$ x length $(\mathrm{mm}) / 2$. Following 4 weeks of tumor growth, the mice mouse was euthanized by cervical dislocation under anesthesia with $1 \%$ pentobarbital $(50 \mathrm{mg} / \mathrm{kg})$ by intraperitoneal injection. The following signs were used to verify death of the mice: Eyes had turned pale, no heartbeat, and they did not respond to external stimuli. The tumors were collected for weight assessment and for RT-qPCR and western blot analyses. All the animal experiments were carried out in accordance with the Ethics Committee of The First Affiliated Hospital of University of South China.

In vivo metastasis study. Ten male nude mice were randomly divided into two groups ( $n=5 /$ group). SW480 cells that exhibited stable knockdown of SNHG20 expression were transfected with firefly luciferase vector (LV16; $100 \mathrm{nM}$; Guangzhou RiboBio Co., Ltd.). Nude mouse (BALB/c-nu/nu; age, 5-6 weeks old; weight, 18-20 g) were anesthetized by intraperitoneal injection of $1 \%$ pentobarbital $(50 \mathrm{mg} / \mathrm{kg})$ and cells ( $2 \times 10^{6}$ LV16-si-SNHG20 SW480 cells) were inoculated into the tail vein. Lung metastases were monitored by bioluminescent imaging for 6 consecutive weeks. All mice were sacrificed at 6 weeks following injection. Before collection of the lungs, the mice were euthanized by cervical dislocation under anesthesia with $1 \%$ pentobarbital $(50 \mathrm{mg} / \mathrm{kg})$ by intraperitoneal injection. The aforementioned indicators were used to verify death. The lung tissue were fixed using $4 \%$ paraformaldehyde at $4^{\circ} \mathrm{C}$ for $24 \mathrm{~h}$ and sections were cut into $4 \mu \mathrm{m}$ pieces. The lung metastatic sites, the number of cells and the corresponding signal intensity were recorded and analyzed by using a small animal live imaging system (PerkinElmer, Inc.; Lumina X5).

Statistical analysis. All statistical analyses were carried out with GraphPad Prism 8.0 software (GraphPad Software, Inc.) or SPSS 20.0 (IBM Corp.). The data are presented as the mean \pm SD. A paired Student's t-test was applied for the 
comparison of matched samples (CRC and normal adjacent tissues). An unpaired t-test was applied for the other comparisons between two groups. For the comparison of multiple groups, one-way ANOVA analysis was performed followed by Tukey's post hoc test. The statistical analysis between the clinical parameters of the patients with CRC and the SNHG20 expression groups was analyzed using a chi-squared test or the Fisher's exact test. Pearson correlation analysis was used to estimate the relationship between the expression level of different gene. All experiments were carried out at least three times. $\mathrm{P}<0.05$ was considered to indicate a statistically significant difference.

\section{Results}

SNHG2O is highly expressed in CRC and is associated with poor prognosis in patients with $C R C$. The expression levels of SNHG20 were measured in 68 pairs of CRC and adjacent normal tissues by RT-qPCR. The results indicated that SNHG20 was highly expressed in CRC tissues (Fig. 1A and B). Similarly, SNHG20 expression was significantly increased in CRC cell lines (HCT116, SW480, SW620 and HT-29) compared with that of the FHC cell line (Fig. 1C). To further explore the clinical significance of SNHG20 expression in CRC, 68 patients with CRC were divided into a high $(n=34)$ and a low expression group $(n=34)$, according to the median expression levels of SNHG20 in all CRC samples. Notably, the clinicopathological data demonstrated that high expression of SNHG20 was significantly associated with tumor size $(\mathrm{P}=0.014)$, tumor invasion depth $(\mathrm{P}=0.019)$, positive lymph node status $(\mathrm{P}=0.022)$, distant metastasis $(\mathrm{P}=0.017)$ and TNM stage $(\mathrm{P}=0.038$; Table II $)$.

Knockdown of SNHG20 causes significant suppression of cell viability, migration and invasion in vitro. Loss of function assays were performed to further assess the biological function of SNHG20. SNHG20 expression was significantly reduced in HCT116 and SW480 cells that were stably transfected with si-SNHG20 (Fig. 1D). MTS and colony formation assays indicated that SNHG20 knockdown significantly suppressed the viability of HCT116 and SW480 cells (Fig. 1E and F). Moreover, Transwell assays revealed that SNHG20 knockdown resulted in a significant reduction of the migratory and invasive activities of HCT116 and SW480 cells (Fig. 1G).

SNHG20 interacts with miR-495 to regulate CRC cell viability, invasion and migration. It has been reported that specific lncRNAs serve as competing endogenous RNAs (ceRNAs) by sponging miRNAs (14). StarBase software was used to predict the target miRNAs of SNHG20. miR-495 was characterized as a potential target of SNHG20 due to its potential complementary sites (Fig. 2A) for SNHG20 and its role as a tumor suppressor in CRC (15). The present study indicated that miR-495 expression levels were significantly downregulated in CRC tissues and cell lines (HCT116, SW480, SW620 and HT-29) (Fig. 2B and C). The miR-495 mimic and inhibitor were transfected into HCT116 and SW480 cell lines. The expression of miR-495 was significantly increased in miR-495 mimic-transfected cells, whereas miR-495 expression was significantly decreased in miR-495 inhibitor-transfected
Table II. Association between SNHG20 expression and clinicopathological factors of CRC.

\begin{tabular}{|c|c|c|c|c|}
\hline \multirow[b]{2}{*}{ Characteristics } & \multirow{2}{*}{$\begin{array}{c}\text { Number of } \\
\text { cases }\end{array}$} & \multicolumn{2}{|c|}{$\begin{array}{l}\text { SNHG20 } \\
\text { expression }\end{array}$} & \multirow[b]{2}{*}{ P-value } \\
\hline & & Low & High & \\
\hline Age, years & & & & 0.627 \\
\hline$<60$ & 32 & 15 & 17 & \\
\hline$\geq 60$ & 36 & 19 & 17 & \\
\hline Sex & & & & 0.874 \\
\hline Male & 30 & 14 & 16 & \\
\hline Female & 38 & 17 & 21 & \\
\hline Tumor size, $\mathrm{cm}$ & & & & $0.014^{\mathrm{a}}$ \\
\hline$<5$ & 28 & 19 & 9 & \\
\hline$\geq 5$ & 40 & 12 & 28 & \\
\hline Tumor invasion depth & & & & $0.019^{\mathrm{a}}$ \\
\hline $\mathrm{T} 1+\mathrm{T} 2$ & 22 & 15 & 7 & \\
\hline $\mathrm{T} 3+\mathrm{T} 4$ & 46 & 19 & 27 & \\
\hline Lymph node status & & & & $0.022^{\mathrm{a}}$ \\
\hline Negative & 19 & 12 & 7 & \\
\hline Positive & 49 & 16 & 33 & \\
\hline Distant metastasis & & & & $0.017^{\mathrm{a}}$ \\
\hline No & 29 & 18 & 11 & \\
\hline Yes & 39 & 14 & 25 & \\
\hline TNM stage & & & & $0.038^{\mathrm{a}}$ \\
\hline $\mathrm{I}+\mathrm{II}$ & 26 & 16 & 10 & \\
\hline III+IV & 42 & 15 & 27 & \\
\hline
\end{tabular}

${ }^{\mathrm{a}} \mathrm{P}<0.05$. SNHG20, small nucleolar RNA host gene 20; TNM, tumor node metastasis.

cells (Fig. 2D).The dual luciferase reporter assays revealed that miR-495 mimics significantly reduced the relative luciferase activity in HCT116 and SW480 cells transfected with pmirGLO-SNHG20-WT (Fig. 2E). In addition, the expression of miR-495 were significantly increased following SNHG20 knockdown (Fig. 2F). Furthermore, Pearson's correlation analysis revealed that miR-495 expression was inversely associated with SNHG20 in CRC tissues ( $\mathrm{r}=-0.53$; $\mathrm{P}<0.001$; Fig. 2G). RIP assays indicated that SNHG20 and miR-495 expression levels were significantly enriched in Ago2-containing microribonucleoprotein complexes (Fig. 2H). Taken together, the data clearly indicated that SNHG20 directly interacted with miR-495.

Subsequently, rescue experiments were performed by transfecting miR-495 inhibitor into SNHG20-knockdown cells. The results suggested that the miR-495 inhibitor reversed the suppressive effects of SNHG20 knockdown on CRC cell viability (Fig. 3A and B), migration and invasion (Fig. 3C). In summary, SNHG20 expression regulated the progression of CRC cells via sponging miR-495.

miR-495 targets STAT3 in CRC. The present study demonstrated that STAT3 was a potential target of miR-495 

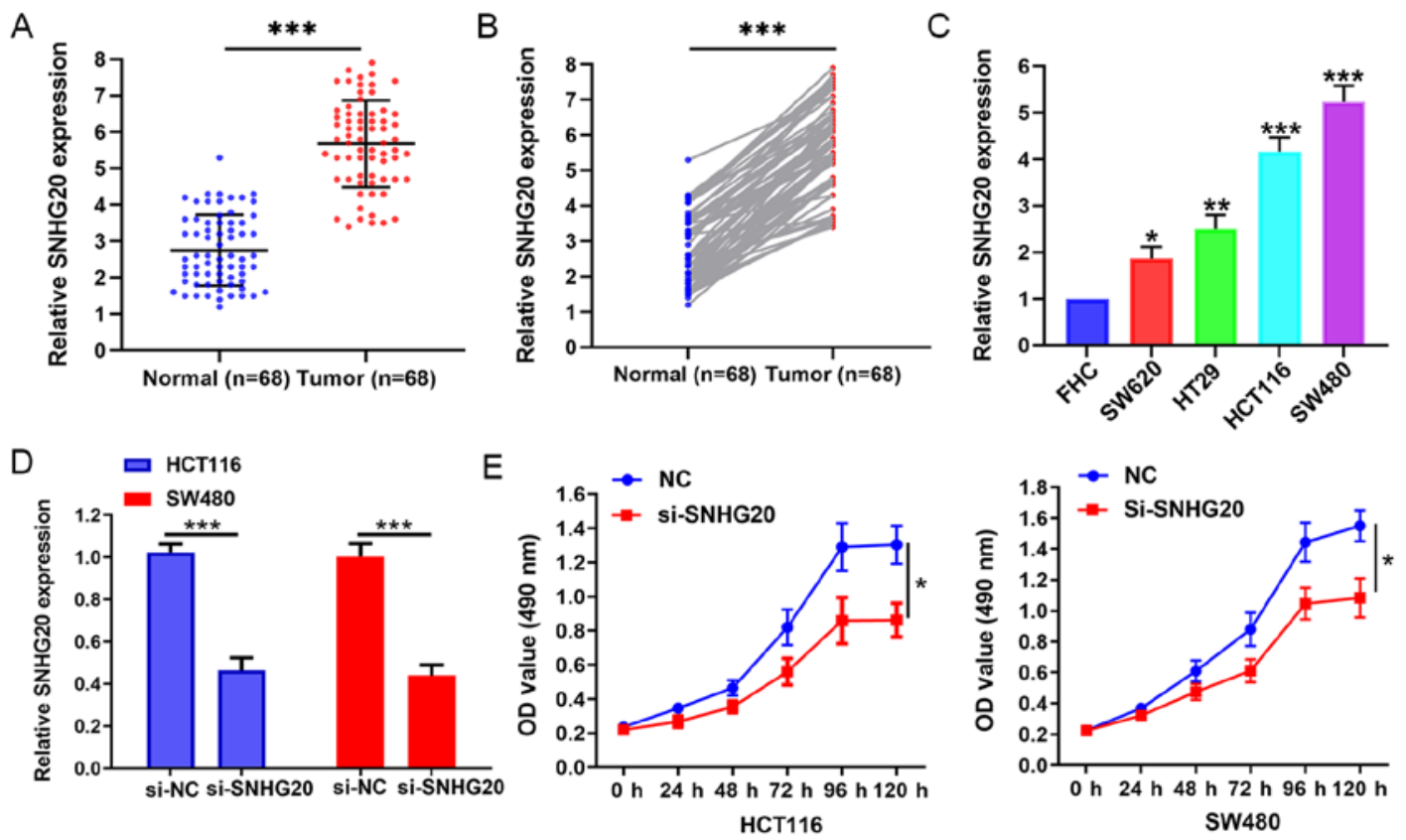

F

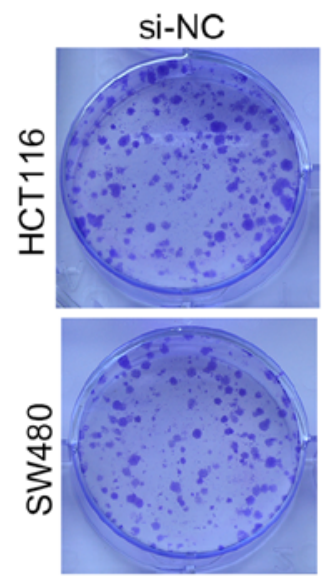

si-SNHG20
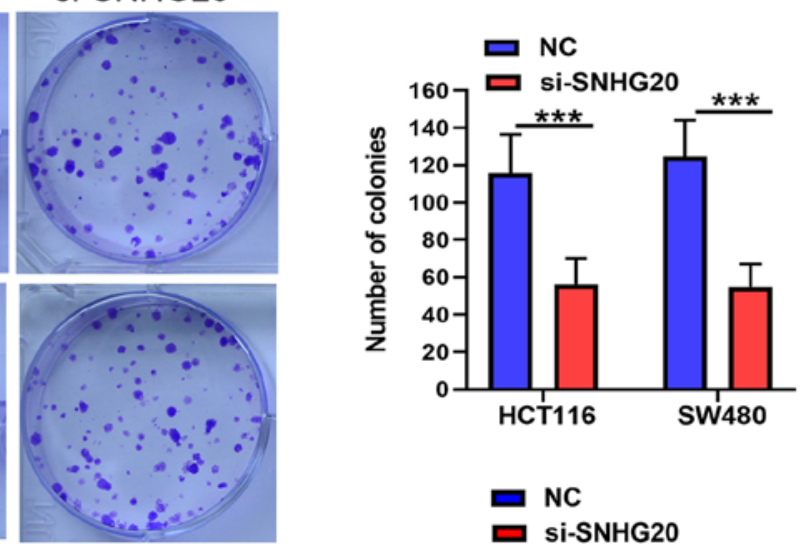

G

si-NC
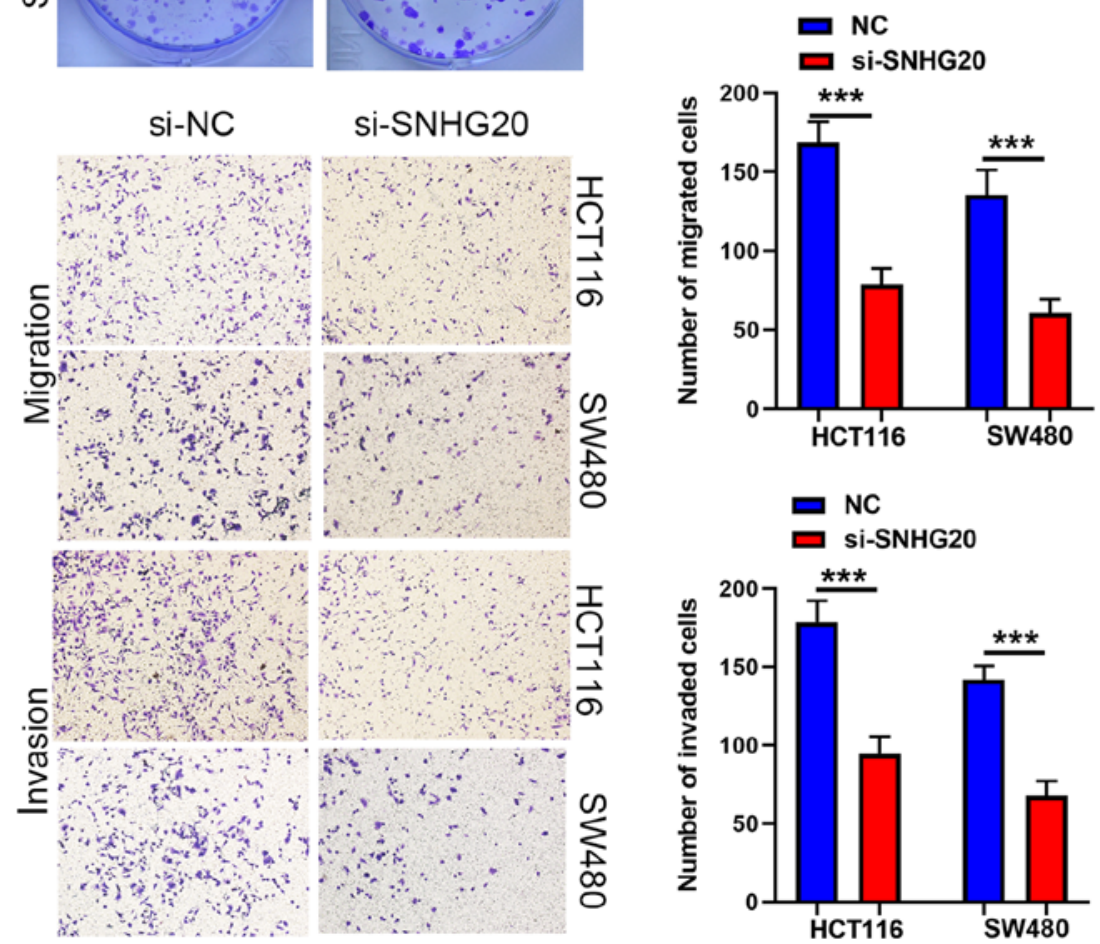

Figure 1. SNHG20 knockdown inhibits proliferation, migration and invasion of CRC cells. (A-C) SNHG20 expression was increased in CRC tissues and CRC cell lines (SW620, HT-29, HCT116, SW480). (D) SNHG20 knockdown efficiency in HCT116 and SW480 cells was examined by reverse transcription-quantitative PCR. (E) MTS and (F) colony formation assays indicated that SNHG20 knockdown inhibited viability of HCT116 and SW480 cells. (G) SNHG20 knockdown inhibited cell invasion and migration of HCT116 and SW480 cells. ${ }^{*} \mathrm{P}<0.05,{ }^{* * *} \mathrm{P}<0.01$ and ${ }^{* * * *} \mathrm{P}<0.001$ vs. FHC cells or as indicated. SNHG20, small nucleolar RNA host gene 20; CRC, colorectal cancer; si-, small interfering RNA; NC, negative control. 
A

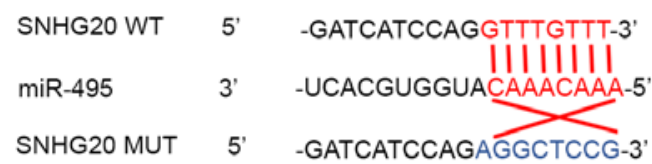

B

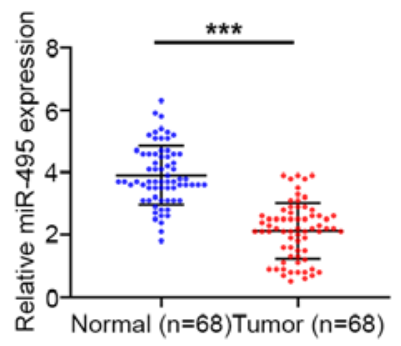

C

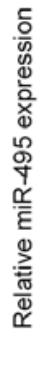
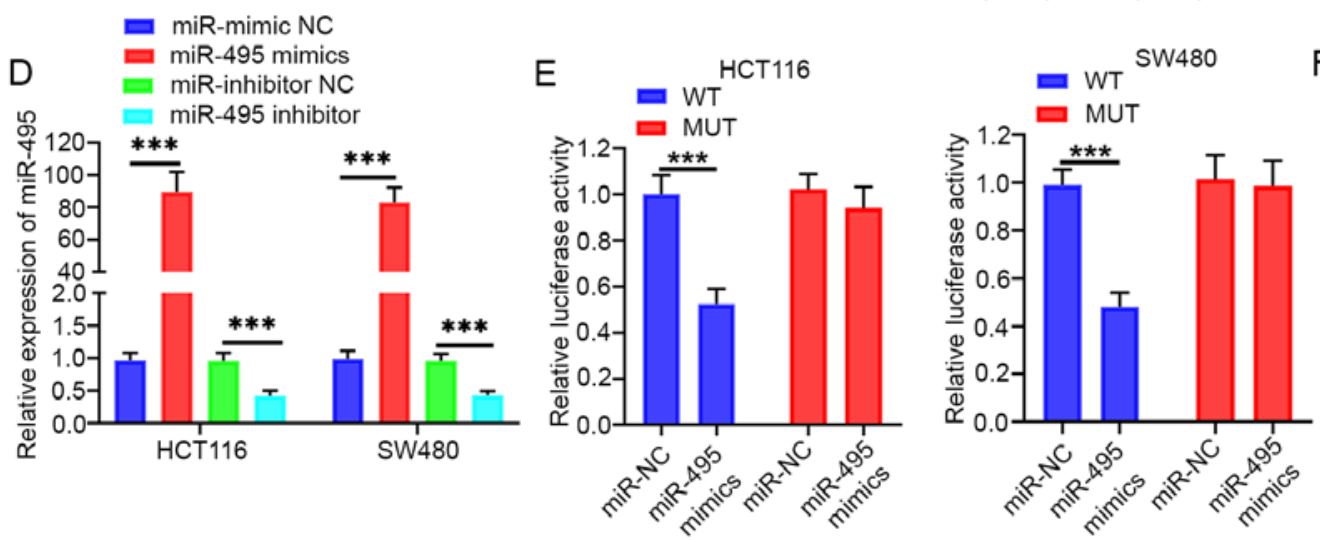

$\mathrm{F}$
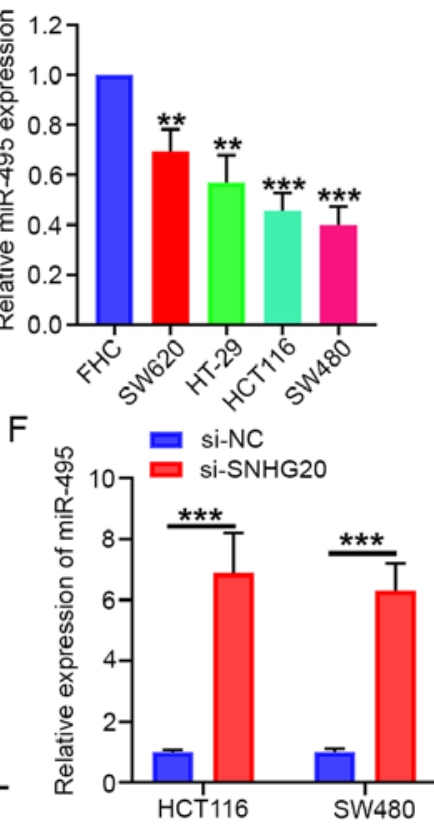

G

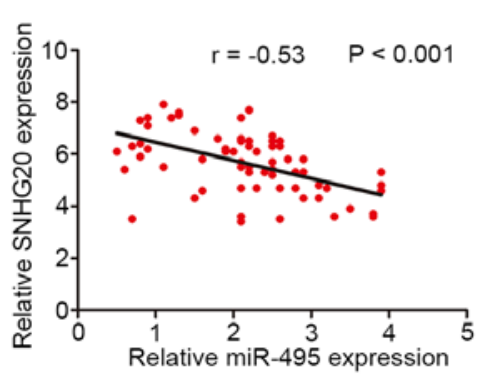

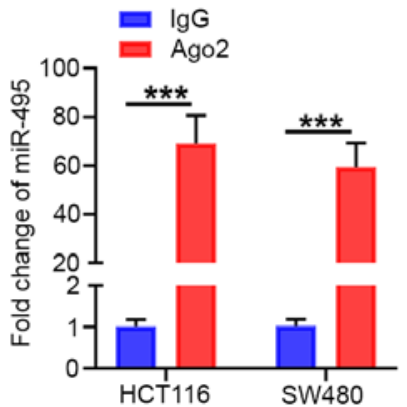

Figure 2. SNHG20 acts as a sponge for miR-495. (A) Predicted binding site of SNHG20 with miR-495, as determined by bioinformatics analysis. (B and C) miR-495 expression levels were significantly decreased in CRC tissues and CRC cell lines (SW620, HT-29, HCT116, SW480). (D) Reverse transcription-quantitative PCR analysis indicated that miR-495 expression was significantly increased in miR-495 mimic-transfected cells, whereas miR-495 expression was significantly decreased in miR-495 inhibitor-transfected cells. (E) Luciferase reporter assay indicated that SNHG20-WT activity was inhibited following transfection of the cells with miR-495 mimics in HCT116 and SW480 cells. (F) SNHG20 knockdown increased the relative expression of miR-495 in HCT116 and SW480 cells. (G) Pearson's correlation analysis indicated that SNHG20 expression was negatively associated with miR-495 in CRC tissues. (H) RNA immunoprecipitation assay demonstrated enrichment of SNHG20 and miR-495 in Ago2-containing beads. ${ }^{* *} \mathrm{P}<0.01$ and ${ }^{* * * *} \mathrm{P}<0.001$ vs. FHC cells or as indicated. SNHG20, small nucleolar RNA host gene 20; CRC, colorectal cancer; miR, microRNA; WT, wild-type; MUT, mutant; si-, small interfering RNA; NC, negative control.

(Fig. 4A). A Previous study reported that STAT3 serves as an oncogene in various cancer types, including CRC (16). The data demonstrated that STAT3 expression levels were significantly upregulated in CRC tissues (Fig. 4B). In addition, Pearson's correlation analysis confirmed that miR-495 expression was associated with STAT3 in CRC tissues $(r=-0.59$; $\mathrm{P}<0.001$; Fig. 4C). The luciferase reporter assay revealed that miR-495 mimics significantly reduced the luciferase activity of STAT3-WT, whereas this effect was not noted for STAT3-MUT (Fig. 4D). In addition, overexpression of miR-495 resulted in a significant decrease in the mRNA and protein expression of STAT3 in both HCT116 and SW480 cells (Fig. 4E and F).

SNHG20 positively regulates STAT3 expression by competitively binding to miR-495. Accumulating evidence has revealed that lncRNAs regulate tumor progression by competing for target miRNAs and modulating mRNA expression (17). Therefore, the present study aimed to investigate whether SNHG20 expression contributed to CRC progression by modulating STAT3 expression. The data indicated that STAT3 mRNA and protein levels were significantly reduced following SNHG20 knockdown. This effect could be partially reversed by the addition of miR-495 inhibitor to the cells (Fig. 5A-C). Moreover, Pearson's correlation analysis confirmed that STAT3 expression was positively correlated with SNHG20 expression in CRC tissues ( $\mathrm{r}=0.48$; $\mathrm{P}<0.001$; Fig. 5D). To further investigate the role of STAT3 and SNHG20 in CRC progression, pcDNA3.1(+) STAT3 was transfected into cells. The mRNA and protein levels of STAT3 were increased significantly following transfection of the cells with pcDNA3.1(+) STAT3 (Fig. 5E and F). In addition, the mRNA and protein levels of STAT3 were significantly reduced following SNHG20 

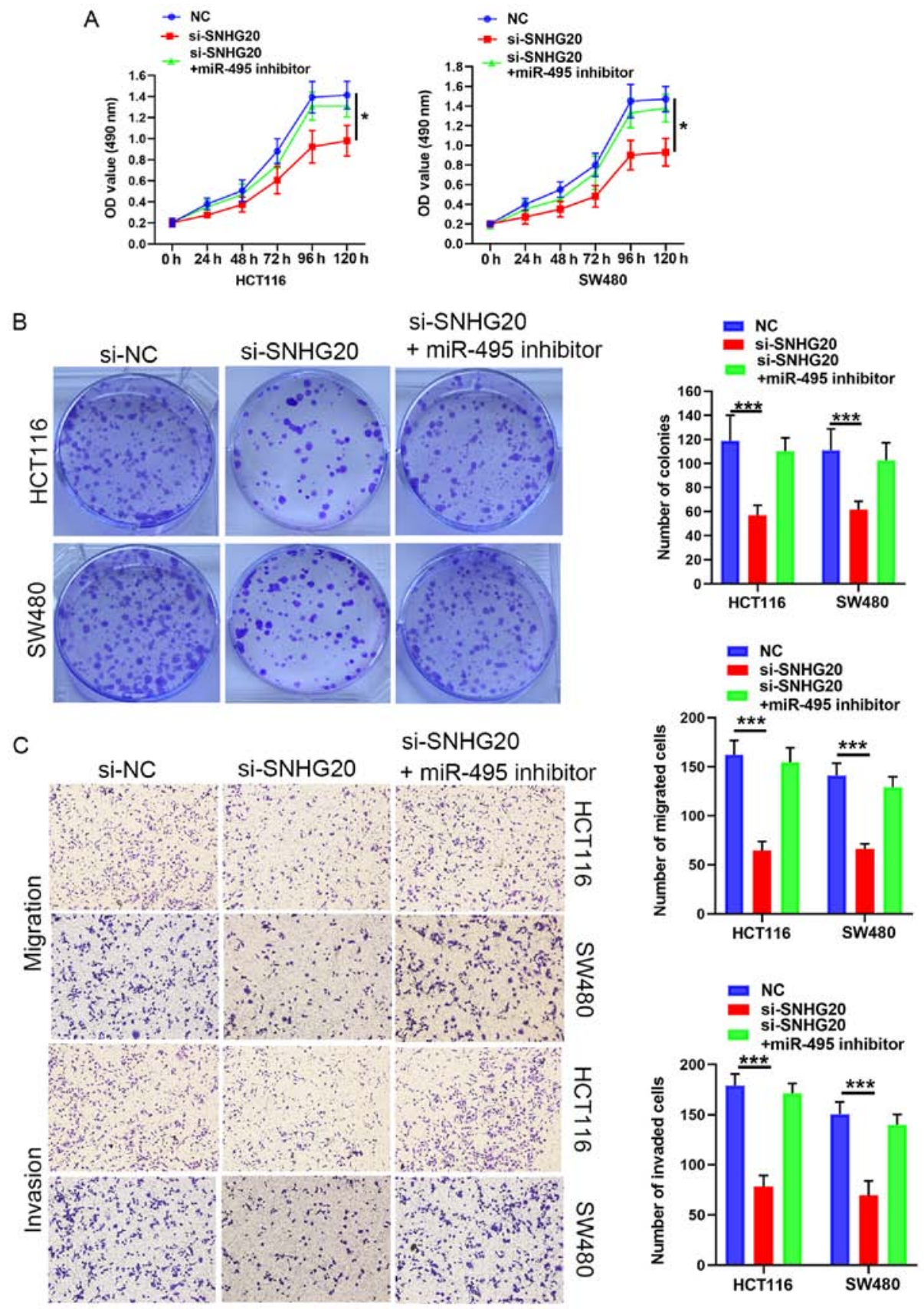

Figure 3. SNHG20/miR-495 axis regulates CRC progression. (A) MTS and (B) colony formation assays indicated that SNHG20 knockdown decreased the cell viability of HCT116 and SW480 cells, which could be reversed by treatment of the cells with the miR-495 inhibitor. (C) Transwell assays showed that SNHG20 knockdown inhibited cell invasion and migration of HCT116 and SW480 cells. This effect could be abolished following treatment of the cells with the miR-495 inhibitor. ${ }^{*} \mathrm{P}<0.05$ and ${ }^{* * * *} \mathrm{P}<0.001$. SNHG20, small nucleolar RNA host gene 20; CRC, colorectal cancer; miR, microRNA; si-, small interfering RNA; NC, negative control.

knockdown, whereas co-transfection of pcDNA3.1(+) STAT3 and si-SNHG20 reversed this inhibitory effect (Fig. 5G and H). Functional assays indicated that STAT3 overexpression could rescue the inhibitory effect of SNHG20 knockdown on cell viability (Fig. 6A and B), migration and invasion (Fig. 6C). In summary, these data demonstrated that SNHG20 facilitated CRC progression by modulating the miR-495/STAT3 axis.

SNHG2O knockdown inhibits tumor growth and metastasis formation in vivo. The tumor volume was significantly smaller in the SNHG20-knockdown group than that noted in the $\mathrm{NC}$ group (Fig. 7A) In addition, the average weight of the tumors in the SNHG20-knockdown group was significantly lower than that noted in the NC group (Fig. 7B). The tumor diameters of the tumors in the SNHG20-knockdown group were significantly smaller than that in the NC group (Fig. 7C). The expression levels of miR-495 in tumor tissues from the SNHG20-knockdown group were higher than those of the NC group as determined by RT-qPCR (Fig. 7D), which was consistent with the in vitro data. However, the expression levels of STAT3 in the SNHG20-knockdown group were significantly lower than those of the NC group (Fig. 7E). The results derived from the in vivo fluorescence imaging indicated that the lowest number of metastatic sites was present in 
A

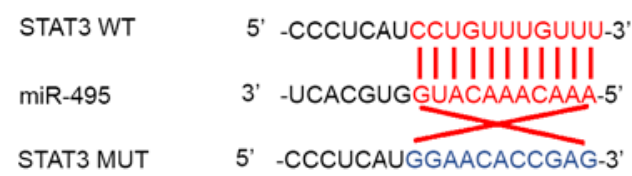

B

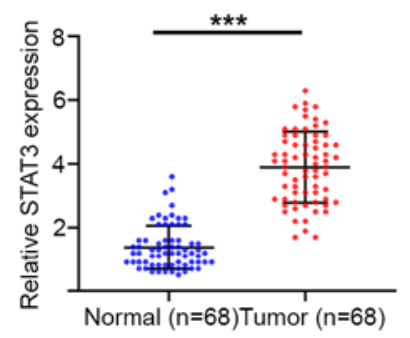

C
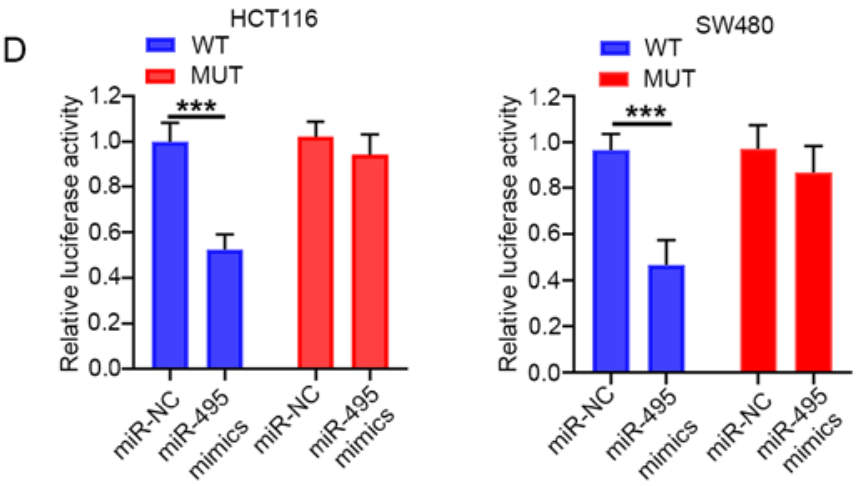

E

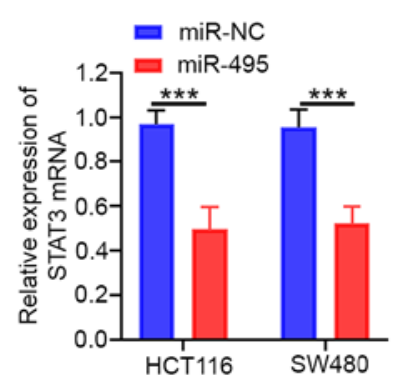

$\mathrm{F}$

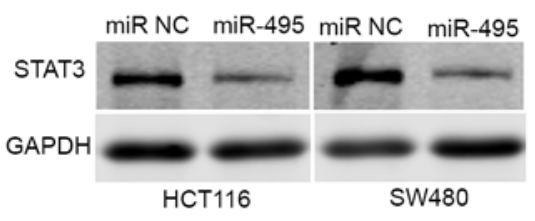

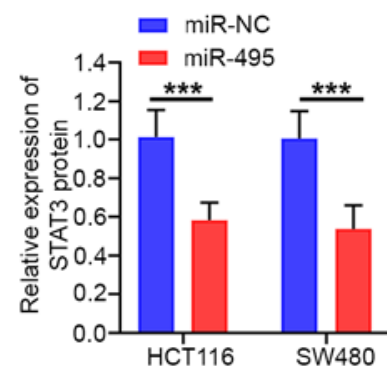

Figure 4. STAT3 expression is negatively regulated by miR-495. (A) Bioinformatics analysis of predicted binding sites between miR-495 and STAT3. (B) The relative expression levels of STAT3 were significantly increased in CRC tissues. (C) Pearson's correlation analysis showed an inverse correlation between miR-495 and STAT3 expression in CRC tissues. (D) Luciferase reporter assays indicated that transfection with the miR-495 mimic significantly reduced the luciferase activity of STAT3-WT in HCT116 and SW480 cells. Overexpression of miR-495 significantly reduced the expression of STAT3 at the (E) mRNA and (F) protein levels in HCT116 and SW480 cells. ${ }^{* * *} \mathrm{P}<0.001$. CRC, colorectal cancer; miR, microRNA; si-, small interfering RNA; NC, negative control; WT, wild-type; MUT, mutant.

the SNHG20-knockdown group, whereas the highest number was found in the NC group (Fig. 7F). In addition, SNHG20 knockdown significantly reduced the number of metastatic pulmonary nodules compared with that in the NC group (Fig. 7G). Taken together, the results indicated that SNHG20 knockdown inhibited CRC growth and metastasis in vivo.

\section{Discussion}

A previous study reported that SNHG20 expression was significantly upregulated in CRC tissues and that this IncRNA was involved in the development and progression of CRC (12). However, the aforementioned study was primarily focused on the association between SNHG20 expression and the clinical features of the subjects. The specific molecular mechanisms of SNHG20 in the progression of CRC are still unclear. In the present study, the expression of SNHG20 was investigated and the data demonstrated that it was significantly increased in CRC. Chi-square and Fisher's exact tests indicated that SNHG20 expression was associated with tumor size, tumor invasion depth, TNM stage, lymph node status and distant metastasis. Functional experiments demonstrated that
SNHG20 silencing suppressed viability, migration and invasion of CRC cells in vitro, and it inhibited CRC growth and metastasis in vivo.

Previous studies have revealed that SNHG20 plays an important role in the development of a multitude of cancers. In gastric cancer, Cui et al (18) demonstrated that high SNHG20 expression was positively associated with poor clinical outcomes. This previous study further demonstrated that SNHG20 silencing inhibited proliferation and invasion of gastric cancer cells. In osteosarcoma, Wang et al (19) reported that SNHG20 silencing notably repressed proliferation and invasion, while enhancing the apoptotic fraction of osteosarcoma cells. In glioma, Li et al (20) demonstrated that SNHG20 expression was upregulated in glioma tissues and cells. Furthermore, they also revealed that SNHG20 silencing led to attenuated vasculogenic mimicry formation in glioma cells (20). The present study reported that SNHG20 expression was significantly upregulated in CRC, which was consistent with the results reported previously.

Mounting evidence has demonstrated that lncRNA acts as a sponge for miRNAs, which further modulate gene expression levels and subsequently participate in several 
A

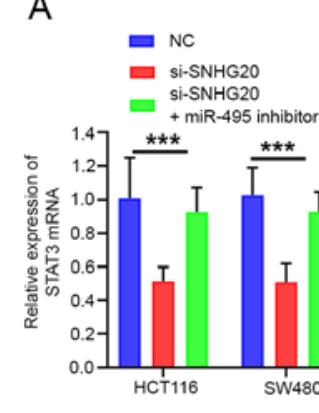

B

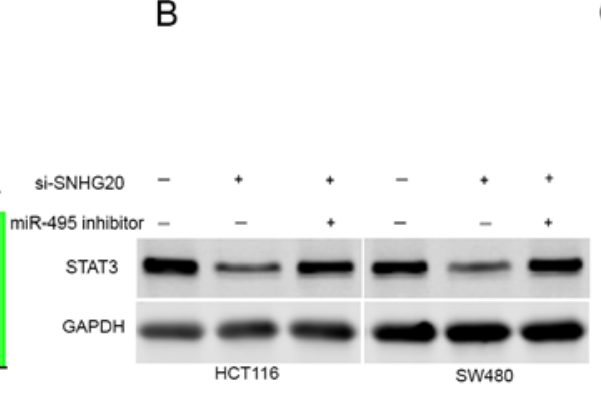

C

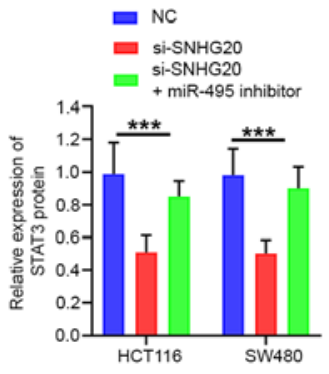

D

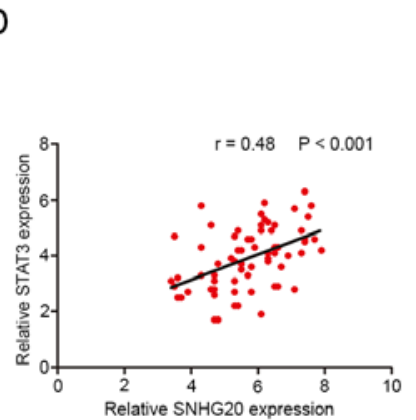

E

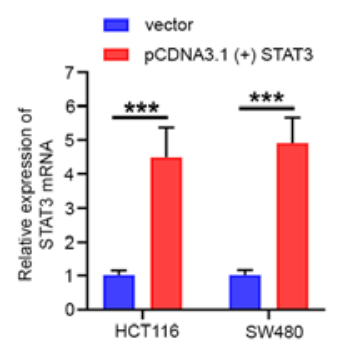

G

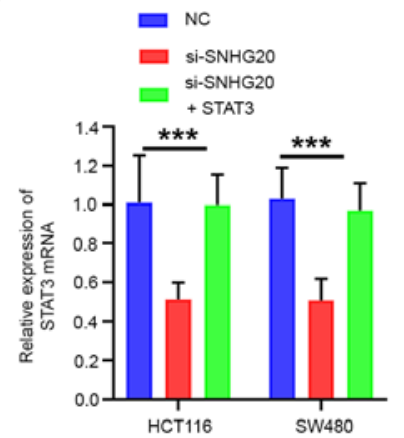

$\mathrm{F}$

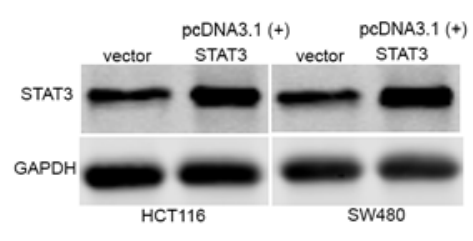

$\mathrm{H}$

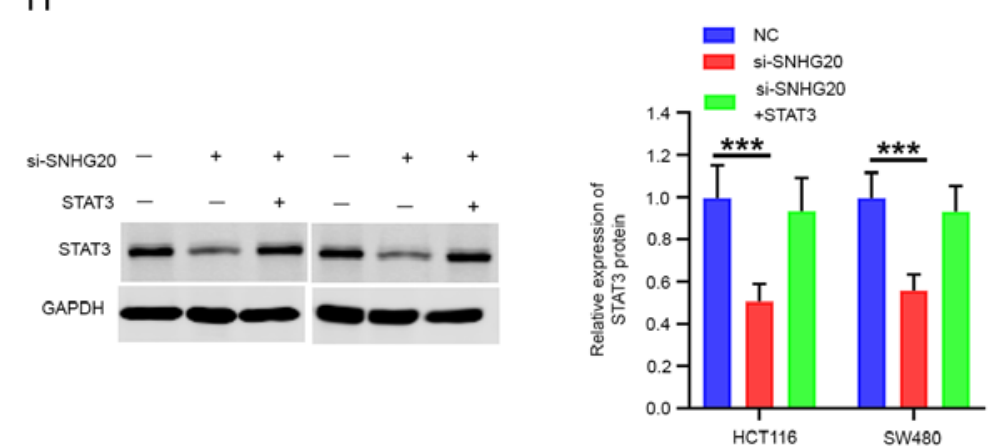

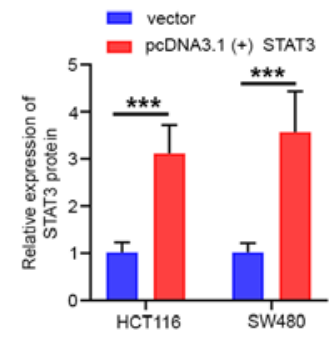

Figure 5. SNHG20 regulates miR-495/STAT3 signaling in CRC. (A-C) SNHG20 knockdown decreased the mRNA and protein expression levels of STAT3, which was reversed by the addition of the miR-495 inhibitor in HCT116 and SW480 cells. (D) Pearson's correlation analysis indicated that SNHG20 expression was positively correlated with STAT3 expression in CRC tissues. (E) Reverse transcription-quantitative PCR and (F) western blotting indicated that the mRNA and protein levels of STAT3 were significantly increased following transfection of the cells with pcDNA3.1(+) STAT3. SNHG20 knockdown decreased the (G) mRNA and $(\mathrm{H})$ protein expression levels of STAT3, which could be reversed by STAT3 overexpression. ${ }^{* * *} \mathrm{P}<0.001$. SNHG20, small nucleolar RNA host gene 20; CRC, colorectal cancer; miR, microRNA; si-, small interfering RNA; NC, negative control.

biological processes, including cell proliferation and metastasis $(7,14)$. However, the target miRNAs of SNHG20 have not been previously identified in CRC. Based on the StarBase software, miR-495 was predicted as a potential target of SNHG20. miR-495 is involved in the development and progression of several tumors. For example, Li et al (21) revealed that miR-495 acted as a tumor suppressor by directly targeting protein tyrosine phosphatase type IVA 3 in human gastric cancer. miR-495 was also reported as an antitumor miRNA in prostate cancer (22), NSCLC (23) and endometrial cancer (24). However, in breast cancer, overexpression of miR-495 was demonstrated to facilitate cell invasion (25). Moreover, Bai et al (26) reported that miR-495 overexpression markedly inhibited invasion and the epithelial-mesenchymal transition of CRC cells. A study by Yan et al (15) indicated that miR-495 expression levels were considerably reduced in CRC tissues and cell lines compared with those of adjacent normal tissues and cell lines. Overexpression of miR-495 significantly inhibited the proliferation, colony formation, migration and invasion of CRC cells (15). He et al (27) demonstrated that miR-495 levels were significantly decreased in CRC cells, and that they were associated with significant suppression of CRC progression. In the present study, the results of the luciferase reporter and RIP assays demonstrated that SNHG20 interacted with miR-495 in CRC cells. In addition, Pearson's correlation analysis further confirmed that SNHG20 expression was negatively associated with miR-495 expression in CRC tissues. Moreover, SNHG20 knockdown significantly increased miR-495 expression in CRC cells. All these data confirmed that SNHG20 contributed to CRC progression via sponging miR-495.

STAT3 is a transcription factor that acts as an oncogene and its expression is upregulated in various human cancers (28). A previous study conducted by Morikawa et al (29) used 724 CRC samples and demonstrated that STAT3 activation was associated with adverse clinical outcomes in CRC. It was reported that inactivation of STAT3 in CRC cells markedly inhibited tumor growth both in vitro and in vivo (30). 
A

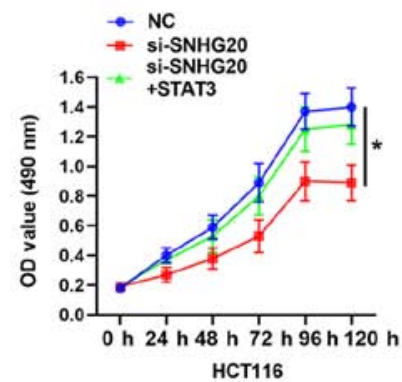

B
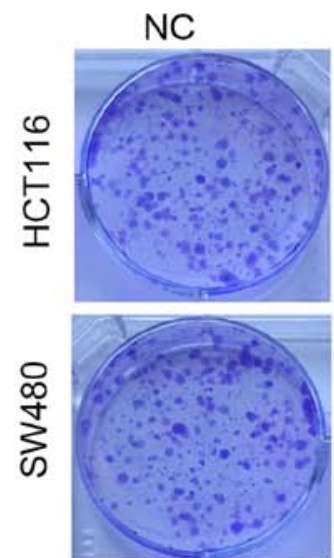

C
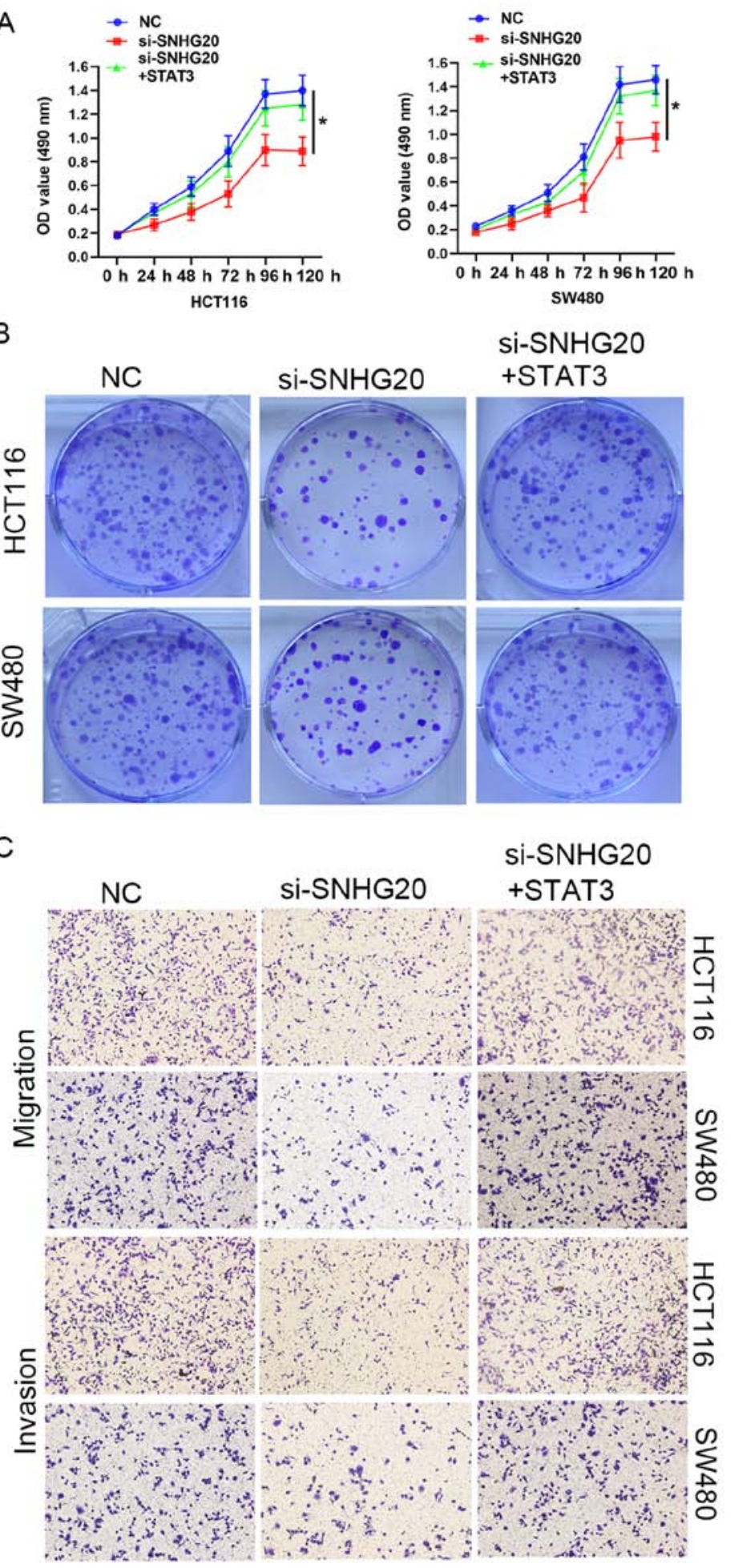

Si-SNHG20 +STAT3
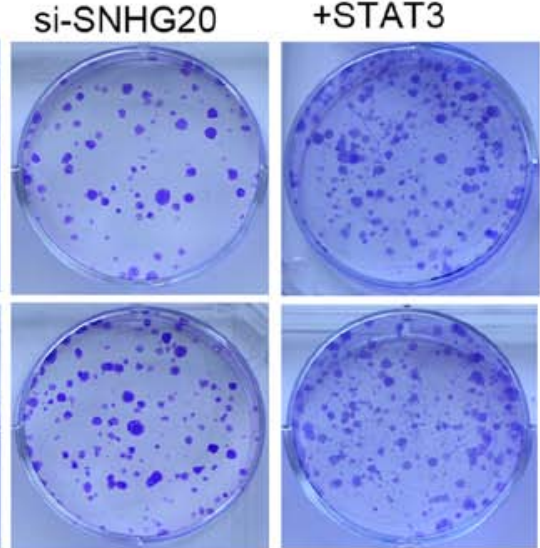
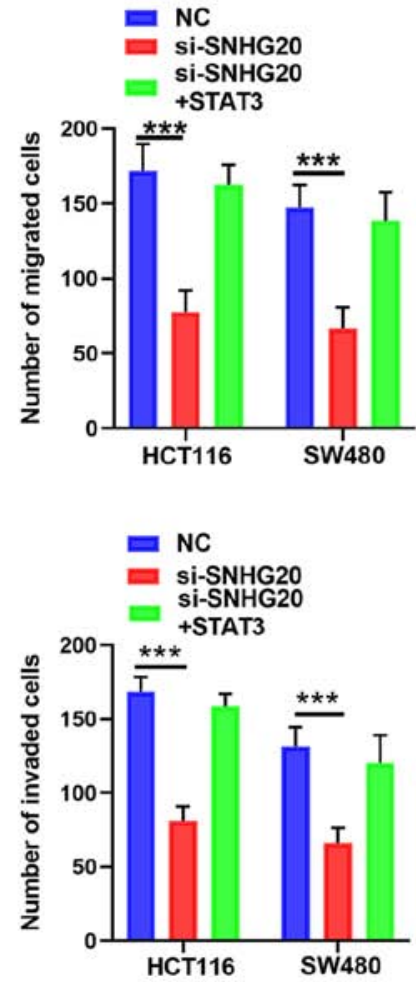

Figure 6. SNHG20/miR-495/STAT3 axis regulates CRC progression. (A) MTS and (B) colony formation assays suggested that SNHG20 knockdown decreased CRC cell viability, which could be reversed by STAT3 overexpression. (C) Transwell assays indicated that SNHG20 knockdown inhibited migration and invasion of CRC cells, which could be reversed by STAT3 overexpression. " $\mathrm{P}<0.05$ and ${ }^{* * * *} \mathrm{P}<0.001$. SNHG20, Small nucleolar RNA host gene 20; CRC, colorectal cancer; miR, microRNA; si-, small interfering RNA; NC, negative control.

In the present study, STAT3 was confirmed as a downstream target of miR-495 in CRC via luciferase reporter assays. In addition, silencing of SNHG20 expression reduced STAT3 expression, whereas co-transfection of the cells with the miR-495 inhibitor reversed the inhibitory effects of SNHG20 silencing on STAT3 expression. Moreover, functional experiments illustrated that co-transfection of the cells with pcDNA3.1-STAT3 rescued the effects of SNHG20 knockdown on viability, migration and invasion of CRC cells.

In summary, the results of the present study demonstrated that SNHG20 promoted viability, migration and invasion of 
A

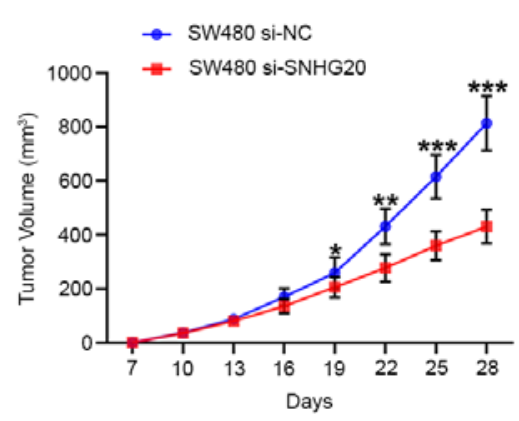

D

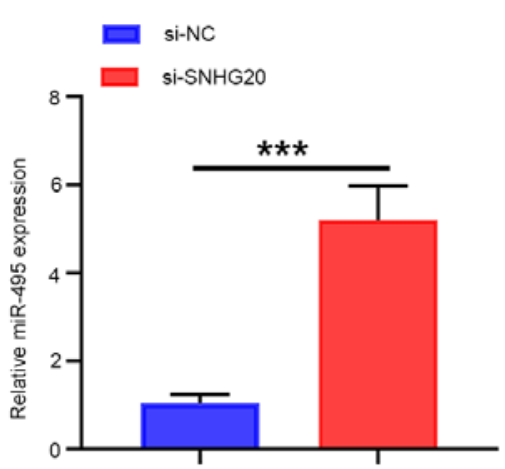

F

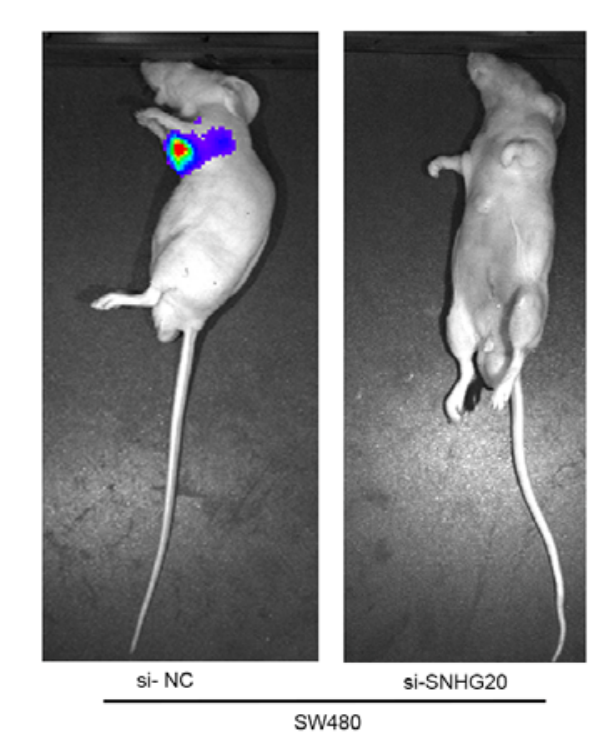

si- NC
B

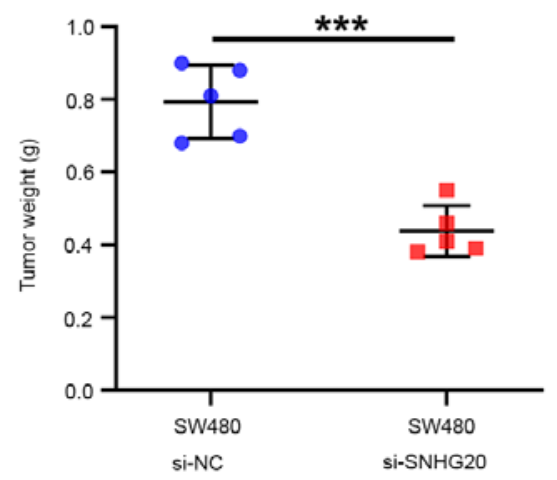

E

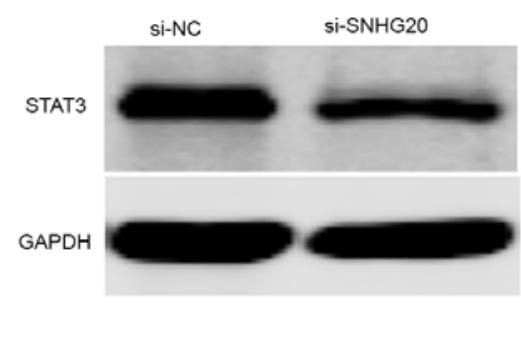

C
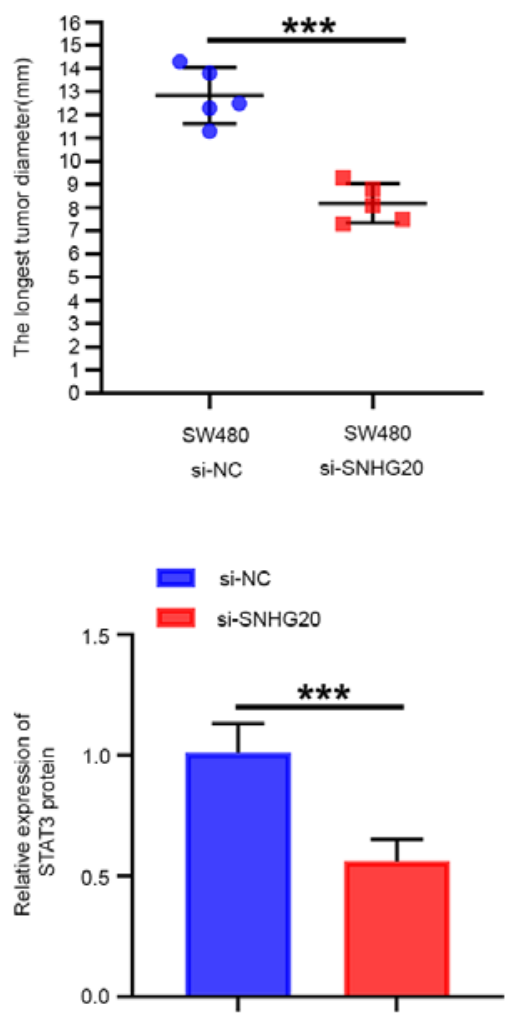

G

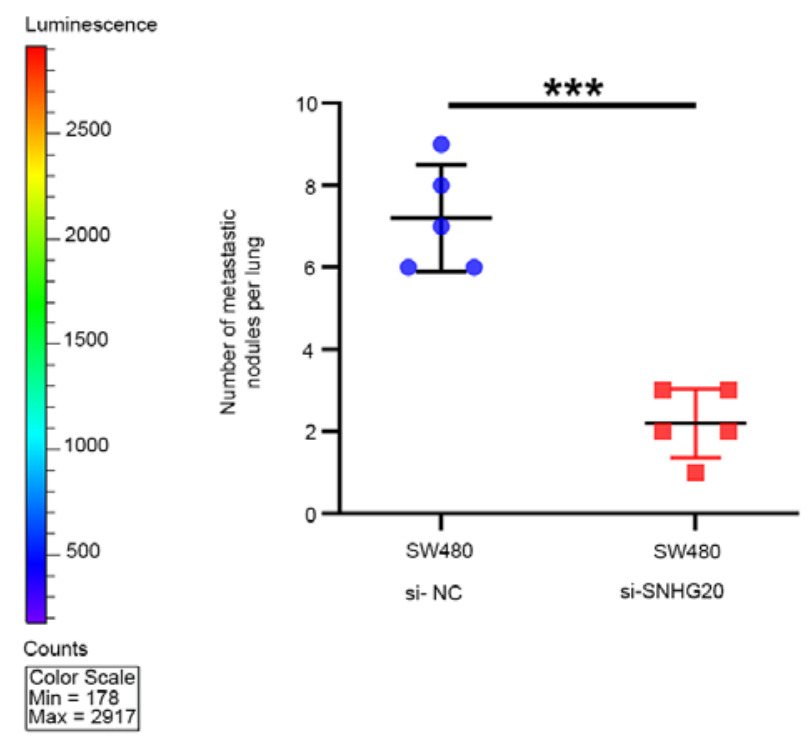

Figure 7. SNHG20 knockdown inhibits CRC growth and metastasis in vivo. (A) The mean volume of the xenograft tumor in the SNHG20-knockdown group was significantly lower than that of the NC group. (B) The average weight of the xenograft tumors in the SNHG20-knockdown group was significantly lower than that noted in the NC group. (C) The longest tumor diameter of the tumors in the SNHG20-knockdown group was significantly smaller than that in the NC group. (D) The relative expression levels of miR-495 in the SNHG20-knockdown group were significantly increased compared with those in the NC group. (E) The relative expression levels of STAT3 in the SNHG20-knockdown group were significantly reduced compared with those in the NC group. (F) Bioluminescence imaging analyses indicated that SNHG20 knockdown significantly inhibited CRC cell lung metastatic ability compared with that of the NC group. (G) SNHG20 knockdown resulted in a significant reduction of the number of metastatic pulmonary nodules compared with that of the NC group. ${ }^{*} \mathrm{P}<0.05,{ }^{* * *} \mathrm{P}<0.01$ and ${ }^{* * * *} \mathrm{P}<0.001$ vs. si-SNHG20 or as indicated. SNHG20, small nucleolar RNA host gene 20; CRC, colorectal cancer; miR, microRNA; si-, small interfering RNA; NC, negative control.

CRC cells. SNHG20 functioned as a ceRNA for miR-495 and upregulated STAT3 expression, which in turn facilitated CRC progression. The SNHG20/miR-495/STAT3 axis may aid the understanding of the molecular mechanism of CRC progression and provide a novel therapeutic target for CRC treatment. 


\section{Acknowledgements}

Not applicable.

\section{Funding}

No funding was received.

\section{Availability of data and materials}

All data generated or analyzed during the present study are available from the corresponding author on reasonable request.

\section{Authors' contributions}

YW and ZL were responsible for conception of the study and the drafting of the manuscript. JF and LY helped to design the study and performed the statistical analysis. ZL revised the manuscript. All authors read and approved the final version of the manuscript.

\section{Ethics approval and consent to participate}

The present study was approved by the Medical Ethics Committee of The First Affiliated Hospital of University of South China (Hengyang, China). Signed informed consent had been provided by all patients. All of the animals experiments were performed under protocols approved by the Institutional Animal Care and Use Committee of The First Affiliated Hospital of the University of South China.

\section{Patient consent for publication}

Not applicable.

\section{Competing interests}

The authors declare that they have no competing interests.

\section{References}

1. Bray F,Ferlay J, Soerjomataram I, Siegel RL, Torre LA and Jemal A: Global cancer statistics 2018: GLOBOCAN estimates of incidence and mortality worldwide for 36 cancers in 185 countries. CA Cancer J Clin 68: 394-424, 2018

2. Dienstmann R, Vermeulen L, Guinney J, Kopetz S, Tejpar S and Tabernero J: Consensus molecular subtypes and the evolution of precision medicine in colorectal cancer. Nat Rev Cancer 17: 79-92, 2017.

3. Sridharan M, Hubbard JM and Grothey A: Colorectal cancer: How emerging molecular understanding affects treatment decisions. Oncology (Williston Park) 28: 110-118, 2014.

4. Fatica A and Bozzoni I: Long non-coding RNAs: New players in cell differentiation and development. Nat Rev Genet 15: 7-21, 2014.

5. Shi X, Sun M, Liu H, Yao Y and Song Y: Long non-coding RNAs: A new frontier in the study of human diseases. Cancer Lett 339: 159-166, 2013.

6. Hua F, Liu S, Zhu L, Ma N, Jiang S and Yang J: Highly expressed long non-coding RNA NNT-AS1 promotes cell proliferation and invasion through wnt $/ \beta$-catenin signaling pathway in cervical cancer. Biomed Pharmacother 92: 1128-1134, 2017.

7. Ge X, Li GY, Jiang L, Jia L, Zhang Z, Li X, Wang R, Zhou M, Zhou Y, Zeng Z, et al: Long noncoding RNA CAR10 promotes lung adenocarcinoma metastasis via miR-203/30/SNAI axis. Oncogene 38: 3061-3076, 2019.

8. Zhang D, Cao C, Liu L and Wu D: Up-Regulation of lncRNA SNHG20 predicts poor prognosis in hepatocellular carcinoma. J Cancer 7: 608-617, 2016.
9. Chen Z, Chen X, Chen P, Yu S, Nie F, Lu B, Zhang T, Zhou Y, Chen Q, Wei C, et al: Long non-coding RNA SNHG20 promotes non-small cell lung cancer cell proliferation and migration by epigenetically silencing of P21 expression. Cell Death Dis 8: e3092, 2017.

10. Wu J, Zhao W, Wang Z, Xiang X, Zhang S and Liu L: Long non-coding RNA SNHG20 promotes the tumorigenesis of oral squamous cell carcinoma via targeting miR-197/LIN28 axis. J Cell Mol Med 23: 680-688, 2019.

11. Wu X, Xiao Y, Zhou Y, Zhou Z and Yan W: lncRNA SNHG20 promotes prostate cancer migration and invasion via targeting the miR-6516-5p/SCGB2A1 axis. Am J Transl Res 11: 5162-5169, 2019.

12. Li C, Zhou L, He J, Fang XQ, Zhu SW and Xiong MM: Increased long noncoding RNA SNHG20 predicts poor prognosis in colorectal cancer. BMC Cancer 16: 655, 2016.

13. Livak KJ and Schmittgen TD: Analysis of relative gene expression data using real-time quantitative PCR and the 2(-Delta Delta C(T)) method. Methods 25: 402-408, 2001.

14. Salmena L, Poliseno L, Tay Y, Kats L and Pandolf PP: A ceRNA hypothesis: The rosetta stone of a hidden RNA language? Cell 146: 353-358, 2011.

15. Yan LK, Yao JF and Qiu J: miRNA-495 suppresses proliferation and migration of colorectal cancer cells by targeting FAM83D. Biomed Pharmacother 96: 974-981, 2017.

16. Zhou C, Tong Y, Wawrowsky K and Melmed S: PTTG acts as a STAT3 target gene for colorectal cancer cell growth and motility. Oncogene 33: 851-861, 2014.

17. Cai Y, Sheng Z, Chen Y and Wang J: LncRNA HMMR-AS1 promotes proliferation and metastasis of lung adenocarcinoma by regulating miR-138/sirt6 axis. Aging (Albany NY) 11: 3041-3054, 2019.

18. Cui N, Liu J, Xia H and Xu D: LncRNA SNHG20 contributes to cell proliferation and invasion by upregulating ZFX expression sponging miR-495-3p in gastric cancer. J Cell Biochem 120: 3114-3123, 2019.

19. Wang W, Luo P, Guo W, Shi Y, Xu D, Zheng H and Jia L: LncRNA SNHG20 knockdown suppresses the osteosarcoma tumorigenesis through the mitochondrial apoptosis pathway by miR-139/RUNX2 axis. Biochem Biophys Res Commun 503: 1927-1933, 2018.

20. Li X, Xue Y, Liu X, Zheng J, Shen S, Yang C, Chen J, Li Z, Liu L, Ma J, Ma T and Liu Y: ZRANB2/SNHG20/FOXK1 axis regulates vasculogenic mimicry formation in glioma. J Exp Clin Cancer Res 38: 68, 2019.

21. Li Z, Cao Y, Jie Z, Liu Y, Li Y, Li Y, Li J, Zhu G, Liu Z, Tu Y, et al: miR-495 and miR-551a inhibit the migration and invasion of human gastric cancer cells by directly interacting with PRL-3. Cancer Lett 323: 41-47, 2012.

22. Li JZ,Wang ZL,Xu WH,LiQ, GaoL and Wang ZM: MicroRNA-495 regulates migration and invasion in prostate cancer cells via targeting akt and mTOR signaling. Cancer Invest 34: 181-188, 2016.

23. Chu H, Chen X, Wang H, Du Y, Wang Y, Zang W, Li P, Li J, Chang J, Zhao $\mathrm{G}$ and Zhang G: miR-495 regulates proliferation and migration in NSCLC by targeting MTA3. Tumour Biol 35: 3487-3494, 2014.

24. Xu YY, Tian J, Hao Q and Yin LR: MicroRNA-495 downregulates FOXC1 expression to suppress cell growth and migration in endometrial cancer. Tumour Biol 37: 239-251, 2016.

25. Hwang-Verslues WW, Chang PH, Wei PC, Yang CY, Huang CK, Kuo WH, Shew JY, Chang KJ, Lee EY and Lee WH: miR-495 is upregulated by E12/E47 in breast cancer stem cells, and promotes oncogenesis and hypoxia resistance via downregulation of E-cadherin and REDD1. Oncogene 30: 2463-2474, 2011.

26. Bai Z, Wang J, Wang T, Li Y, Zhao X, Wu G, Yang Y, Deng W and Zhang Z: The miR-495/Annexin A3/P53 axis inhibits the invasion and EMT of colorectal cancer cells. Cell Physiol Biochem 44: 1882-1895, 2017.

27. He Z, Dang J, Song A, Cui X, Ma Z and Zhang Z: NEAT1 promotes colon cancer progression through sponging miR-495-3p and activating CDK6 in vitro and in vivo. J Cell Physiol 234: 19582-19591, 2019.

28. Yuan J,Zhang F and Niu R: Multiple regulation pathways and pivotal biological functions of STAT3 in cancer. Sci Rep 5: 17663, 2015.

29. Morikawa T, Baba Y, Yamauchi M, Kuchiba A, Nosho K, Shima K, Tanaka N, Huttenhower C, Frank DA, Fuchs CS and Ogino S: STAT3 expression, molecular features, inflammation patterns and prognosis in a database of 724 colorectal cancers. Clin Cancer Res 17: 1452-1462, 2011.

30. Zhang P, Zhao Y, Zhu X, Sedwick D, Zhang X and Wang Z: Cross-Talk between phospho-STAT3 and PLC $\gamma 1$ plays a critical role in colorectal tumorigenesis. Mol Cancer Res 9: 1418-1428, 2011.

This work is licensed under a Creative Commons Attribution-NonCommercial-NoDerivatives 4.0 International (CC BY-NC-ND 4.0) License. 